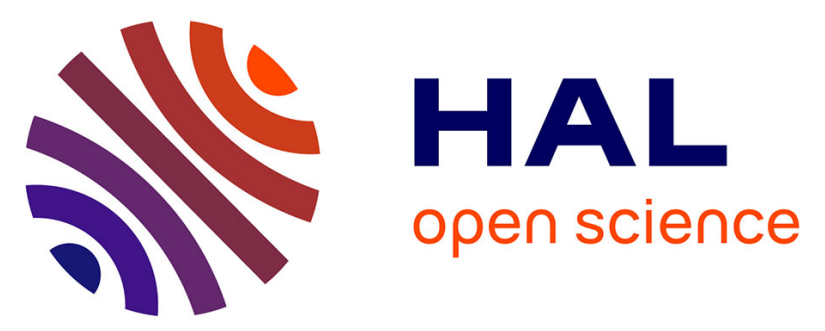

\title{
The effect of long-term danazol prophylaxis on liver function in hereditary angioedema-a longitudinal study
} Henriette Farkas, Ibolya Czaller, Dorottya Csuka, Anikó Vas, Szilvia Valentin, Lilian Varga, Gábor Széplaki, László Jakab, George Füst, Zoltán Prohászka, et al.

\section{To cite this version:}

Henriette Farkas, Ibolya Czaller, Dorottya Csuka, Anikó Vas, Szilvia Valentin, et al.. The effect of long-term danazol prophylaxis on liver function in hereditary angioedema-a longitudinal study. European Journal of Clinical Pharmacology, 2009, 66 (4), pp.419-426. 10.1007/s00228-009-0771-z . hal-00548159

\section{HAL Id: hal-00548159 \\ https://hal.science/hal-00548159}

Submitted on 19 Dec 2010

HAL is a multi-disciplinary open access archive for the deposit and dissemination of scientific research documents, whether they are published or not. The documents may come from teaching and research institutions in France or abroad, or from public or private research centers.
L'archive ouverte pluridisciplinaire HAL, est destinée au dépôt et à la diffusion de documents scientifiques de niveau recherche, publiés ou non, émanant des établissements d'enseignement et de recherche français ou étrangers, des laboratoires publics ou privés. 


\title{
The effect of long-term danazol prophylaxis on liver function in hereditary angioedema—a longitudinal study
}

\author{
Henriette Farkas • Ibolya Czaller • Dorottya Csuka • Anikó Vas • Szilvia Valentin • \\ Lilian Varga • Gábor Széplaki • László Jakab • George Füst • Zoltán Prohászka • \\ George Harmat • Beata Visy • István Karádi
}

Received: 29 June 2009 / Accepted: 24 November 2009/Published online: 19 December 2009

(C) Springer-Verlag 2009

\begin{abstract}
Background Danazol is a drug most widely used for the prophylaxis of hereditary angioedema resulting from the deficiency of the $\mathrm{C} 1$-inhibitor. Potential hepatotoxic or liver tumor-inducing side effects of long-term danazol prophylaxis have been investigated during the follow-up of hereditary angioedema patients.

Methods Characteristic parameters of liver function (including bilirubin, GOT, GPT, $\gamma \mathrm{GT}$, total protein, ALP, LDH), as well as findings of viral serology screens and abdominal ultrasonography-determined during years 0 and 5 of follow-up of patient groups taking/not taking danazol-have been reviewed and analyzed comparatively. Results From a population of 126 hereditary angioedema patients, 46 subjects taking danazol and another 46 not taking danazol fulfilled the inclusion criteria. Longitudinal follow-up did not reveal any clinically relevant difference between the liver function parameters determined in years 0
\end{abstract}

H. Farkas $(\bowtie) \cdot$ I. Czaller • D. Csuka $\cdot$ L. Varga $\cdot$ G. Széplaki •

L. Jakab $\cdot$ G. Füst $\cdot$ Z. Prohászka $\cdot$ I. Karádi

Faculty of Medicine, 3rd Department of Internal Medicine,

Semmelweis University,

Kútvölgyi út 4,

H-1125 Budapest, Hungary

e-mail: farkash@kut.sote.hu

A. Vas

Department of Radiology, Kútvölgyi Clinical Centre,

Budapest, Hungary

\section{S. Valentin}

Central Laboratory, Kútvölgyi Clinical Centre,

Budapest, Hungary

G. Harmat • B. Visy

Heim Pál Pediatric Hospital,

Budapest, Hungary and 5 in the two groups. Abdominal ultrasound did not detect neoplastic or other potentially treatment-related alterations of the liver parenchyma. There were no discontinuations of treatment during the study.

Conclusions Our results clearly suggest that, administered at the lowest effective dose, danazol does not induce liver injury in hereditary angioedema patients.

Keywords C1-inhibitor deficiency - Treatment .

Ultrasound · Safety · Side effect · Danazol · Liver function

$\begin{array}{ll}\text { Abbreviations } \\ \text { GOT } & \text { Glutamate-oxaloacetate transaminase } \\ \text { GPT } & \text { Glutamate-pyruvate transaminase } \\ \gamma \mathrm{GT} & \text { Gamma-glutamyltransferase } \\ \text { ALP } & \text { Alkaline phosphatase } \\ \text { LDH } & \text { Lactate dehydrogenase } \\ \text { HAE } & \text { Hereditary angioedema } \\ \text { C1-INH } & \text { C1-inhibitor } \\ \text { pdhC1- } & \text { Plasma-derived human C1-inhibitor concen- } \\ \text { INH } & \text { trate } \\ \text { AAS } & \text { Anabolic androgen steroid } \\ \text { LDL } & \text { Low-density lipoprotein }\end{array}$

\section{Introduction}

Hereditary angioedema (HAE) - a disorder of autosomal dominant inheritance-results from the deficiency of the $\mathrm{C} 1$-inhibitor (C1-INH) gene. It is characterized by paroxysms of edema formation in the subcutis and/or the submucosa of the upper airways and the gastrointestinal tract [1-3]. Edema formation is attributed largely to bradykinin released during the activation of various plasma 
cascade (e.g., fibrinolytic, coagulation, complement, and contact) systems.

The management of HAE comprises two essential stages: the therapy of overt attacks and prevention of their recurrence. Currently, plasma-derived human C1-INH (pdhC1-INH) concentrate or bradykinin-receptor antagonist is the remedy of choice to relieve acute attacks $[1,4-6]$. Agents appropriate for short- or long-term prophylaxis in clinical practice include antifibrinolytic agents and attenuated anabolic steroids (danazol, stanozolol, oxandrolone), as well as pdhC1-INH concentrate in certain cases $[1,4,7$, 8]. In 1955, Spaulding published the first paper about the beneficial effect of methyltestosterone in HAE [9]. Anabolic steroids were introduced into the clinical management of HAE in 1976, and an abundance of reports have confirmed their effectiveness since then [10-15]. Nowadays, a 17-alpha-alkylated anabolic androgen steroid (AAS) known as danazol is the most commonly used prophylactic drug, the exact mode of action of which has not yet been elucidated [16-18].

Danazol can prevent the occurrence of attacks in the majority of patients and can reduce attack frequency and severity. The following side effects can be expected during its administration: virilization, masculinization, deeping of the voice, hair loss, clitoral/penile enlargement, amenorrhea, hirsutism, libido changes, androgen-induced premature closure of epiphyses in children, psychiatric and behavioral effects, depression, aggressive behavior, flushing, diaphoresis, vaginal dryness, irritation, diminution of breasts, glucose intolerance, insulin resistance, hypogonadism, testicular atrophy, reduction of HDL cholesterol and elevation of LDL cholesterol levels, and hepatotoxicity [19]. A substantial proportion of studies appraising the side effects of treatment with danazol were conducted in patients with endometriosis, although large patient populations with idiopathic thrombocytopenic purpura (ITP) were also studied [20-22]. Unfortunately, experience from these studies is not fully suitable for extrapolation to HAE patients, owing to differences in treatment duration and danazol dosage [22].

Adverse reactions observed in HAE patients receiving danazol have been reported in review articles and clinical summaries [4, 14, 23]. Major side effects of danazol in HAE patients include proatherogenic changes in lipid profile [24], hepatotoxicity, elevated liver enzyme activity, cholestatic jaundice, peliosis hepatis, and various neoplastic lesions. The hepatotoxic effect of danazol has been discussed in a limited number of predominantly crosssectional studies and case reports; no longitudinal studies have been undertaken yet [13, 25-30]. Since patients are concerned about side effects - especially liver injury - and often decline treatment with this effective agent (which is almost the sole remedy available in many countries), the objective of our study was to clarify the effects of long-term danazol treatment on liver function.

\section{Methods}

Study design

Retrospective analysis of data accumulated in the Hungarian HAE Registry since 1995 was performed. Laboratory parameters informative of liver function (serum bilirubin, GOT, GPT, $\gamma \mathrm{GT}$, total protein, ALP, LDH), results of viral serology tests, and findings of abdominal ultrasonographyall obtained once a year at least - were reviewed. In addition to positive family history and presence of clinical manifestations, inclusion criteria also comprised known HAE, confirmed by complement studies and followed-up for 4 years at least.

Patients who had been taking danazol without interruption for at least 4 years were eligible for enrollment in the danazol group. Subjects who had been followed up for a minimum of 4 years and underwent laboratory testing at least annually, but had not received danazol until the end of the study period were eligible for inclusion in the control group.

Initial data from 'year 0 ' were defined as baseline parameters (obtained during a 1-year period at maximum) before the initiation of danazol treatment. Only data recorded later than 1995 were taken into account, in order to ensure the use of standard methodology and reference ranges in all patients, as this was considered a prerequisite for making meaningful comparisons. Danazol treatment of six patients had started before 1995 and accordingly, their year 0 data were chosen from the period after 1995. 'year 5' data were defined as the follow-up information recorded at a time closest to 5 years after obtaining the corresponding year 0 data.

The reference ranges of serum bilirubin, GOT, GPT, $\gamma \mathrm{GT}$, and total protein remained essentially unchanged during the 5-year study period. In the case of ALP and $\mathrm{LDH}$, however, reference ranges had changed and therefore, test results obtained after 1 February 2001 were considered year 0 values in patients receiving danazol. Thus, post-baseline values (recorded after the start of danazol treatment) were taken into account for 26 subjects.

The longitudinal study was implemented by comparing year 0 and year 5 laboratory values within the individual study groups. The abdominal ultrasonography study compared the latest follow-up abdominal/liver ultrasonography findings obtained in the two groups with each other.

Occasionally, danazol dose was adjusted as required by attack frequency and therefore, the potential influence of danazol dose on laboratory parameters was assessed in view of the cumulative dose taken by individual subjects. In 
patients who had been taking danazol longer than 5 years, the latest parameters were adjusted according to the actual duration of danazol treatment. The parameters of patients receiving danazol for more than 10 years were analyzed separately.

\section{Study subjects}

All 126 HAE patients registered with and managed at the Hungarian HAE Center as of July 2008 were included in this study and treated according to the Budapest protocol [4].

\section{Patients taking danazol}

Fifty-eight of the 126 patients underwent danazol prophylaxis (according to registry records as of July 2008). The daily dose ranged from 33 to $200 \mathrm{mg}$; however, occasionally it was escalated to $300-400 \mathrm{mg} /$ day temporarily. Seven patients did not fulfill the requirement of 4 years of danazol treatment and four of these patients were excluded. The remaining three patients had been followed up extensively during the period before danazol was introduced, and therefore, this earlier period made them eligible for inclusion into the control group. An additional three patients were withdrawn from the study after all of them had been ascertained to suffer from severe alcohol dependence. Finally, two other patients who received danazol only briefly were also excluded from the 5-year study.

Thus, the danazol group comprised 46 patients (22 males and 24 females). These subjects did not receive other prophylactic agents or any other drug with known potential for causing liver damage.

\section{Patients not taking danazol}

Sixty-eight patients had never received danazol; the duration of follow-up was shorter than 4 years in 24 of these. An additional subject was excluded for alcoholism. On the other hand, the three patients referred to above (with sufficiently long follow-up before the initiation of danazol treatment) were included in the control group. Thus, the control group consisted of 46 HAE patients (15 males and 31 females), none of whom received prophylactic drugs or were treated with tranexamic acid for long-term prophylaxis. The study was approved by the institutional review board and all subjects gave informed consent. Table 1 summarizes the descriptive statistics of the two patient groups.

\section{Laboratory procedures}

Laboratory measurement of liver function parameters was performed using computerized laboratory analyzers. Cobas
Integra 400/800 (Roche, Basel, Switzerland) was used for measuring serum bilirubin, GOT, GPT, $\gamma \mathrm{GT}$, ALP, LDH, and total protein levels. Virus serology (screening for HBsAg, anti-HCV) was performed upon enrollment and at every subsequent control visit.

Ultrasonography of the abdomen and liver

Screening of liver status comprised appraising the size (relative to the lower pole of the kidney), structure, and (increased/reduced) echogenicity (in comparison to that of the renal parenchyma) of the liver, as well as evaluation of intrahepatic biliary passages and the condition of the gall bladder.

The liver parenchyma was reviewed for the presence of circumscribed, focal lesions, and abnormalities of the portal and hepatic veins were actively sought. Detected lesions were grouped according to diagnosis as well as the above considerations (Table 6). Comparisons were made between the groups taking vs. not-taking danazol. The proportion of young patients was greater in the group not receiving danazol.

\section{Statistical analysis}

Calculations were performed with SPSS for Windows v13.0 (SPSS, Chicago, IL, USA) and Prism v4.00 (GraphPad Software, San Diego, CA, USA). Since many variables had non-Gaussian distributions, we used Wilcoxon's nonparametric test for year 0 and year 5 comparisons, whereas Spearman's rho-coefficient was used to calculate correlations. Fisher's exact test was also performed. Values presented in the text are medians (with minimummaximum range).

The level of two-tailed significance was set at $P<0.05$ $(2 \alpha=0.05,95 \%$ confidence $)$.

\section{Results}

Longitudinal study

Within the group not treated with danazol, no significant differences could be demonstrated between the group of children and adolescents $(<18$ years old, young group $)$ and adults ( $\geq 18$ years old, adult group). In the adult group, no significant changes occurred during the follow-up period in any of the laboratory parameters tested (Table 2).

In the young group a significant decrease in GOT and $\mathrm{LDH}$, as well as a significant increase in $\gamma \mathrm{GT}$ and total protein levels was ascertained.

Changes in the laboratory parameters in patients treated with danazol during the 5-year follow-up period are 
Table 1 Descriptive statistics of the two patient groups

\begin{tabular}{llll}
\hline & & Treated with danazol & Not treated with danazol \\
\hline Subjects & Number & 46 & 46 \\
Age at the start of the study (years) & Median (min-max) & $32.5(9-62)$ & $16(2-73)$ \\
Sex & Male/female & $22 / 24$ & $15 / 31$ \\
& Percentage & $47.83 / 52.17$ & $32.61 / 67.39$ \\
HAE type & I:II & $41 / 5$ & $43 / 3$ \\
& Percentage & $89.13 / 10.87$ & $93.48 / 6.52$ \\
Duration of follow-up (year) & Median $(25 ; 75)$ & $5.03(4.76 ; 5.37)$ & $5.05(4.58 ; 5.41)$ \\
& Mean & 5.009 & 5.003 \\
Daily dose (mg) & Median $(25 ; 75)$ & $98.44(55.21 ; 146.3)$ & - \\
Cumulative dose over 5 years $(\mathrm{g})$ & Mean & 108 & - \\
& Median $(25 ; 75)$ & $184.1(102.4 ; 274.8)$ & - \\
\end{tabular}

summarized in Table 3. No significant changes occurred in bilirubin or GOT levels. The most marked changes occurred in the LDH levels; in both groups they dropped, and the decrease was more marked in the adult group. GPT and $\gamma \mathrm{GT}$ levels were weakly or marginally significantly higher in year 5 than in year 0 . In spite of this, however, $92.4 \%$ of these values were within the reference range in year 5 . There were differences between the two age groups in some parameters: total protein levels increased only in the adult group, while ALP levels diminished only in the young group.

By the end of the fifth year, values of 14 subjects (30.4\% of the group) exceeded the reference range, including two patients with simultaneous elevation of two ( $\gamma \mathrm{GT}$ and total protein) out of the seven studied parameters. In these 14 subjects, the elevation of values exceeded the upper limit of the reference range by $14.1 \%$ on average. In the group not taking danazol, the values of 16 parameters were above the reference range in 12 patients (21.6\% of the group). A decrease below the lower limit of the reference range was seen with LDH level only.

There was no difference in the liver function parameters between male and female patients in either treatment group.

In the danazol-treated group, two formerly seropositive patients (one each) were infected by the hepatitis $\mathrm{B}$ and hepatitis $\mathrm{C}$ virus, respectively. One patient in the control group was HBV positive. Although the source of infection could not be identified in any of these cases, its relation to either HAE or to treatment with C1-INH can be ruled out with certainty. All three patients are in remission currently
Table 2 Year 0 and year 5 laboratory parameters for patients not treated with danazol

\begin{tabular}{lllllc}
\hline & Number & Group & $\begin{array}{l}\text { Year } 0 \\
\text { Median }(\text { min-max })\end{array}$ & $\begin{array}{l}\text { Year } 5 \\
\text { Median (min-max) }\end{array}$ & $\begin{array}{l}\text { Wilcoxon } \\
P \text {-value }\end{array}$ \\
\hline Bilirubin & 19 & $\geq 18$ years & $9.5(5-23.1)$ & $9.3(4.5-24.2)$ & 0.968 \\
& 27 & $<18$ years & $8.6(4.1-24)$ & $10.9(4.3-29.8)$ & 0.249 \\
GOT & 19 & $\geq 18$ years & $20(8-50)$ & $17(11-41)$ & 0.369 \\
& 27 & $<18$ years & $27(15-58)$ & $18(11-32)$ & $<0.0001$ \\
GPT & 19 & $\geq 18$ years & $16(8-111)$ & $15(9-70)$ & 0.663 \\
& 27 & $<18$ years & $15(9-28)$ & $15(10-30)$ & 0.518 \\
$\gamma$ GT & 19 & $\geq 18$ years & $15(10-161)$ & $20(9-116)$ & 0.093 \\
& 27 & $<18$ years & $12(9-21)$ & $14(9-33)$ & 0.006 \\
Total protein & 19 & $\geq 18$ years & $73(67-86)$ & $73(67-83)$ & 0.537 \\
& 27 & $<18$ years & $72(62-81)$ & $76(64-84)$ & $<0.0001$ \\
ALP & 21 & $\geq 18$ years & $76(41-129)$ & $77(49-132)$ & 0.237 \\
& 25 & $<18$ years & $160(54-363)$ & $92(41-413)$ & 0.069 \\
LDH & 21 & $\geq 18$ years & $165(135-227)$ & $146(124-241)$ & 0.126 \\
& 25 & $<18$ years & $220(144-427)$ & $155(114-281)$ & $<0.0001$ \\
\hline
\end{tabular}


Table 3 Year 0 and year 5 laboratory parameters for patients treated with danazol

\begin{tabular}{|c|c|c|c|c|c|}
\hline Danazol-treated subjects & Number & Group & $\begin{array}{l}\text { Year } 0 \\
\text { Median (min-max) }\end{array}$ & $\begin{array}{l}\text { Year } 5 \\
\text { Median (min-max) }\end{array}$ & $\begin{array}{l}\text { Wilcoxon } \\
P \text { value }\end{array}$ \\
\hline \multirow[t]{2}{*}{ Bilirubin } & 39 & $\geq 18$ years & $12.2(5.5-40.4)$ & $10.8(5.4-44.5)$ & 0.295 \\
\hline & 7 & $<18$ years & $9.8(5.5-11.8)$ & $11.1(7.7-14.6)$ & 0.204 \\
\hline \multirow[t]{2}{*}{ GOT } & 39 & $\geq 18$ years & $20(13-55)$ & $20(13-34)$ & 0.200 \\
\hline & 7 & $<18$ years & $23(19-35)$ & $22(16-31)$ & 0.350 \\
\hline \multirow[t]{2}{*}{ GPT } & 39 & $\geq 18$ years & $18(8-85)$ & $22(10-47)$ & 0.021 \\
\hline & 7 & $<18$ years & $18(9-24)$ & $26(9-30)$ & 0.058 \\
\hline \multirow[t]{2}{*}{$\gamma \mathrm{GT}$} & 39 & $\geq 18$ years & $18(5-59)$ & $23(9-48)$ & 0.031 \\
\hline & 7 & $<18$ years & $14(9-18)$ & $19(9-38)$ & 0.046 \\
\hline \multirow[t]{2}{*}{ Total protein } & 39 & $\geq 18$ years & $72(63-79)$ & $74(63-82)$ & 0.003 \\
\hline & 7 & $<18$ years & $72(69-79)$ & $73(71-82)$ & 0.292 \\
\hline \multirow[t]{2}{*}{ ALP } & 38 & $\geq 18$ years & $69.5(38-201)$ & $67(40-122)$ & 0.159 \\
\hline & 8 & $<18$ years & $197(61-366)$ & $73.5(60-138)$ & 0.025 \\
\hline \multirow[t]{2}{*}{ LDH } & 38 & $\geq 18$ years & $170(107-251)$ & $150(108-216)$ & $<0.0001$ \\
\hline & 8 & $<18$ years & $165.5(124-202)$ & $151.5(107-180)$ & 0.012 \\
\hline
\end{tabular}

and exhibit no differences compared to the normal population as regards liver enzyme activity, laboratory parameters, and findings of hepatic ultrasonography.

There was no correlation between the cumulative dose of danazol during the follow-up period and the 5-year laboratory parameters (Table 4).

In patients who had been taking danazol for more than 5 years $(n=36)$, no correlation could be ascertained between the duration of drug treatment and the latest determined values of liver function parameters (from 2007 and 2008). Mean duration of danazol treatment was 8.58 years in this subset.

All follow-up data from patients who had been treated with danazol for more than 10 years without interruption were aggregated for the descriptive analysis presented in Table 5. As evidenced by these data-occasional outliers notwithstanding - all monitored parameters have persisted heretofore in the reference range.

Abdominal and hepatic ultrasonography

Pre-existing liver disease was not identified in the medical and family history of patients at enrollment. All three above-mentioned patients with hepatitis are in remission currently, and their condition is checked regularly by a hepatologist. Abdominal ultrasound (US) findings were available for all 46 patients taking danazol, but only for 38 subjects in the control group. Comparison of the US findings of these two groups revealed a circumscribed, focal lesion or other abnormality in a single case only. This, however, is unrelated to danazol treatment, as the lesion had been detected before treatment was initiated. At that time, diagnostic work-up was supplemented by native and contrast-enhanced abdominal $\mathrm{CT}$, which identified the 7-mm lesion found in the right lobe of the liver as a benign hemangioma. Biopsy was not performed. Monitoring of the lesion regularly for 4 years has not detected any change in its size. Abnormalities of hepatic status, diagnoses, and number of cases in the two groups are set out in Table 6. Analysis of these data with Fisher's exact tests did not reveal any significant difference between the two groups (Table 6). Mean duration of the time that elapsed before the occurrence of the lesions identified was 5.97 years.

In view of these results, no differences were found by abdominal ultrasonography in comparison to controls.

Table 4 Correlation between the cumulative dose of danazol during the follow-up period and the 5-year laboratory parameters

\begin{tabular}{|c|c|c|c|c|c|c|c|c|}
\hline Spearman's rho & Year 5 values & Bilirubin $_{5}$ & $\mathrm{GOT}_{5}$ & $\mathrm{GPT}_{5}$ & $\gamma \mathrm{GT}_{5}$ & Total protein $_{5}$ & $\mathrm{ALP}_{5}$ & $\mathrm{LDH}_{5}$ \\
\hline \multirow[t]{3}{*}{ Cumulative dose over 5 years $(\mathrm{g})$} & Correlation coefficient & -0.251 & -0.108 & -0.083 & -0.034 & -0.162 & -0.149 & -0.037 \\
\hline & $P$ (two-tailed) & 0.092 & 0.474 & 0.585 & 0.824 & 0.283 & 0.325 & 0.806 \\
\hline & Number & 46 & 46 & 46 & 46 & 46 & 46 & 46 \\
\hline
\end{tabular}


Table 5 Descriptive analysis of patients treated with danazol continuously for more than 10 years

\begin{tabular}{|c|c|c|c|c|c|c|c|c|}
\hline Patient no. & Sex & $\begin{array}{l}\text { Bilirubin } \\
(\mu \mathrm{mol} / \mathrm{l})\end{array}$ & GOT (U/l) & GPT U/1 & $\gamma \mathrm{GT} \mathrm{U} / 1$ & $\begin{array}{l}\text { Total protein } \\
(\mathrm{g} / \mathrm{l})\end{array}$ & Mean daily dose (mg) & Duration of treatment (years) \\
\hline 7 & M & $7.7(5-10.3)$ & $21(18-31)$ & $25(13-38)$ & $14(12-29)$ & $75(70-76)$ & 81 & 10 \\
\hline 10 & $\mathrm{~F}$ & $\begin{array}{l}19.1(10.5- \\
28.2)\end{array}$ & $20(18.51)$ & $19(12-66)$ & $18(10-50)$ & $73(66-86)$ & 91 & 10.7 \\
\hline 12 & $\mathrm{~F}$ & $10.3(8-14.2)$ & $20(16-32)$ & $22(15-41)$ & $12(10-16)$ & $72.5(70-76)$ & 170 & 10.72 \\
\hline 15 & M & $7.8(3-13.3)$ & $20.5(11-48)$ & $26(9-107)$ & $25(16.78)$ & $69(56-75)$ & 200 & 21.9 \\
\hline 17 & M & $8.4(4.7-11.6)$ & $19(12-33)$ & $15(8-30)$ & $15(10-23)$ & $69(66.79)$ & 136 & 11.81 \\
\hline 18 & M & $10.9(6.4-26.1)$ & $23.5(14-43)$ & $\begin{array}{l}22.5(13- \\
47)\end{array}$ & $13(10-19)$ & $76(72-82)$ & 51 & 10.99 \\
\hline 20 & $\mathrm{~F}$ & $8(5.5-12.5)$ & $28(21-32)$ & $36(24-45)$ & $38(24-71)$ & $74(68-78)$ & 59 & 10.37 \\
\hline 24 & $\mathrm{~F}$ & $10(5-17)$ & $25.5(14-41)$ & $17(9-41)$ & $29(13.81)$ & $68.5(62-74)$ & 196 & 20.18 \\
\hline 31 & $\mathrm{~F}$ & $11(8.5-16.5)$ & $20(15-39)$ & $14(11-37)$ & $16(11-28)$ & $70(63-76)$ & 164 & 12.87 \\
\hline 35 & M & $13.5(3.3-27.1)$ & $26(15-40)$ & $34(19-53)$ & $40(13-85)$ & $72(66-74)$ & 100 & 16.68 \\
\hline 36 & M & $8.5(4.5-11.1)$ & $29(22-50)$ & $31(15-76)$ & $33(13-76)$ & $74(72-75)$ & 123 & 16.68 \\
\hline 37 & $\mathrm{~F}$ & $11(2.3-19)$ & $36.5(26-45)$ & $35(22-60)$ & $34(24-63)$ & $76.5(73-81)$ & 141 & 16.68 \\
\hline 40 & $\mathrm{~F}$ & $11(5-15.6)$ & $24(16-37)$ & $22(14-38)$ & $38(12-84)$ & $73(68-85)$ & 190 & 12.13 \\
\hline
\end{tabular}

\section{Discussion}

As demonstrated by our findings, long-term prophylaxis with danazol is associated with only minor changes in hepatic function and does not induce ultrasound-detectable structural alterations in the liver.

The first half of the study compared liver function parameters from year 0 and year 5 of patients taking/not taking danazol and described the values of patients treated with danazol for more than 5 or 10 years. Minimal and clinically unimportant elevation of any of the seven monitored parameters above the upper limit of the reference range was ascertained in 14 patients taking danazol. The significant elevation of $\gamma$ GT levels might be attributed toamong others causes - the known tendency of $\gamma$ GT activity to increase with age. Statistical calculations showed a clear correlation in this respect [31]. In the case of bilirubin, deviation from the reference range might have been influenced by Gilbert's disease, diagnosed in 4 subjects. Notwithstanding this, no clinically relevant difference in

Table 6 Results of abdominal ultrasonography for group treated with danazol and group not treated with danazol

\begin{tabular}{llll}
\hline & Group not treated with danazol & Group treated with danazol & $P$ value (Fischer's exact test) \\
\hline By types of lesions & & & 0.7469 \\
Hepatomegaly & $4(10.5 \%)$ & $7(15.2 \%)$ & 1.0000 \\
Diffuse hepatic lesions & $4(10.5 \%)$ & $5(10.9 \%)$ & 1.0000 \\
Cholelithiasis & $2(5.3 \%)$ & $2(4.3 \%)$ & 1.0000 \\
Sludge & $0(0 \%)$ & $1(2.2 \%)$ & 1.0000 \\
Focal sparing & $1(2.6 \%)$ & $1(2.2 \%)$ & 0.4986 \\
Liver cyst & $0(0 \%)$ & $2(4.3 \%)$ & 0.6850 \\
Haemangioma & $2(5.3 \%)$ & $4(8.7 \%)$ & 0.2676 \\
All lesions & $13(34.2 \%)$ & $22(47.8 \%)$ & 0.7469 \\
All patients & $38(100 \%)$ & $46(100 \%)$ & 0.6229 \\
By observed abnormalities & $4(10.5 \%)$ & $7(15.2 \%)$ & 0.7777 \\
Hepatomegaly & $1(2.6 \%)$ & $3(6.5 \%)$ & 1.0000 \\
Parenchymal reflectivity $\downarrow$ & $6(15.8 \%)$ & $9(19.6 \%)$ & 0.2676 \\
Parenchymal reflectivity $\uparrow$ & $2(5.3 \%)$ & $3(6.5 \%)$ & $22(47.8 \%)$ \\
Lesion in gall bladder & $13(34.2 \%)$ & $46(100 \%)$ & \\
All lesions & $38(100 \%)$ & & \\
All patients & & &
\end{tabular}


GOT and total bilirubin levels emerged over 5 years. The increase in GPT level was significant, although all changes were confined within the reference range. During followup, ALP level decreased significantly in young patients taking danazol. This may be explained by the fact that the skeletal growth of subjects - who had been of pediatric age at the start of danazol treatment-concluded during the study period. ALP levels did not change significantly in the group not taking danazol; this is attributed to the large proportion of subjects still in the stage of skeletal growth within this group. A highly significant decrease in LDH level occurred in both groups, regardless of the type of treatment. This was an unexpected finding. No accurate explanation for this phenomenon is available yet. Total protein level followed an increasing trend, which is related to the anabolic effect of danazol; an opposite change would occur in hepatic impairment.

No correlation was found between the cumulative dose of danazol and the values of laboratory parameters measured at the end of the 5-year period, again indicating that there is no strong relationship between the danazol treatment and liver function. Liver function parameters were not related to the duration of drug treatment.

No clinically relevant changes were seen in the laboratory parameters of patients who have been taking danazol for more than 10 years. The occasional occurrence of outliers was a transitory phenomenon, as evidenced by their normalization despite ongoing danazol treatment, as well as the elimination of underlying causes transient in nature (infections, gallstones).

No substantial differences could be ascertained between the groups with regards to the parameters of male and of female patients. The results are in agreement with the findings from cross-sectional studies conducted by other researchers, that is, danazol does not cause clinically significant alteration of liver function parameters when administered at the lowest effective dose [12, 13, 32, 33].

Ultrasonographic appearance of the liver was not different between the groups taking/not taking danazol. No adenoma or cancer was found in the hepatic region. A circumscribed lesion was detected in one patient, but its etiology was unrelated to danazol treatment. Hepatic adenomas and cancer described during danazol therapy of other disorders might have been related to high -400 to 600 or occasionally $800 \mathrm{mg}$ - daily doses administered over several years, as well as to insufficient patient monitoring [21, 26-28, 34-37]. Of note, Bork reported cases with benign liver tumors that developed during low-dose treatment for longer than 10 years. Therefore, treatment duration seems important, in addition to drug dose. Evidently, other individual factors may have their role, as no ultrasonographic abnormalities suggestive of a neoplas- tic change could be detected in the liver in any of our patients who had taken danazol longer than 10 years.

Severe complications (hepatic rupture, hemorrhage, peliosis, malignant transformation) can be prevented by early recognition of liver tumors. Discontinuation of danazol may achieve regression or disappearance of small, benign neoplasms. In the case of larger and usually symptomatic tumors (causing abdominal pain) located beneath the capsule, surgical removal (partial or hemihepatectomy) is recommended along with discontinuation of danazol [28, 29, 37]. When necessary, C1-INH substitution should be considered.

Thus, it may be concluded that danazol-which has been in clinical use for more than three decades - did not induce any significant alterations of liver function parameters or the development of progressive hepatic lesions or tumors detectable by ultrasonography when administered according to the long-term treatment protocol adopted by our institution. No drug-related adverse reactions warranting treatment discontinuation were observed during this study. The importance of determining the lowest effective dose must be emphasized-along with the importance of repeating laboratory screening and abdominal ultrasonography at least annually. These check-ups afford early recognition of side effects and thereby create the opportunity for dosage adjustment or treatment discontinuation.

Acknowledgments We thank Márta Kókai, Judit Hajas, Éva Páskuly, and Judit Bali for their excellent laboratory assistance.

Declaration on all sources of funding None

\section{References}

1. Agostoni A, Aygoren-Pursun E, Binkley KE, Blanch A, Bork K, Bouillet L et al (2004) Hereditary and acquired angioedema: problems and progress: proceedings of the third $\mathrm{C} 1$ esterase inhibitor deficiency workshop and beyond. J Allergy Clin Immunol 114:S51-S131

2. Carugati A, Pappalardo E, Zingale LC, Cicardi M (2001) C1inhibitor deficiency and angioedema. Mol Immunol 38:161173

3. Frank MM (2006) Hereditary angioedema: the clinical syndrome and its management in the United States. Immunol Allergy Clin North Am 26:653-668

4. Bowen T, Cicardi M, Bork K, Zuraw B, Frank M, Farkas H et al (2008) Hereditary angiodema: a current state-of-the-art review, VII: Canadian Hungarian 2007 International Consensus Algorithm for the Diagnosis, Therapy, and Management of Hereditary Angioedema. Ann Allergy Asthma Immunol 100:S30-S40

5. Gompels MM, Lock RJ, Abinun M, Bethune CA, Davies G, Grattan C et al (2005) C1 inhibitor deficiency: consensus document. Clin Exp Immunol 139:379-394

6. Farkas H, Jakab L, Temesszentandrasi G, Visy B, Harmat G, Fust $\mathrm{G}$ et al (2007) Hereditary angioedema: a decade of human C1- 
inhibitor concentrate therapy. J Allergy Clin Immunol 120:941947

7. Zuraw BL (2008) Hereditary angiodema: a current state-of-the-art review, IV: short- and long-term treatment of hereditary angioedema: out with the old and in with the new? Ann Allergy Asthma Immunol 100:S13-S18

8. Sloane DE, Lee CW, Sheffer AL (2007) Hereditary angioedema: safety of long-term stanozolol therapy. J Allergy Clin Immunol 120:654-658

9. Spaulding WB (1955) Hereditary angioneurotic oedema in two families. Can Med Assoc J 73(3):181-187

10. Gelfand JA, Sherins RJ, Alling DW, Frank MM (1976) Treatment of hereditary angioedema with danazol. Reversal of clinical and biochemical abnormalities. N Engl J Med 295:1444-1448

11. Hosea SW, Santaella ML, Brown EJ, Berger M, Katusha K, Frank MM (1980) Long-term therapy of hereditary angioedema with danazol. Ann Intern Med 93:809-812

12. Cicardi M, Bergamaschini L, Cugno M, Hack E, Agostoni G, Agostoni A (1991) Long-term treatment of hereditary angioedema with attenuated androgens: a survey of a 13-year experience. J Allergy Clin Immunol 87:768-773

13. Bork K, Bygum A, Hardt J (2008) Benefits and risks of danazol in hereditary angioedema: a long-term survey of 118 patients. Ann Allergy Asthma Immunol 100:153-161

14. Banerji A, Sloane DE, Sheffer AL (2008) Hereditary angioedema: a current state-of-the-art review, V: attenuated androgens for the treatment of hereditary angioedema. Ann Allergy Asthma Immunol 100:S19-S22

15. Church JA (2004) Oxandrolone treatment of childhood hereditary angioedema. Ann Allergy Asthma Immunol 92:377-378

16. Johnson AM, Alper CA, Rosen FS, Craig JM (1971) C1 inhibitor: evidence for decreased hepatic synthesis in hereditary angioneurotic edema. Science 173:553-554

17. Drouet C, Desormeaux A, Robillard J, Ponard D, Bouillet L, Martin L et al (2008) Metallopeptidase activities in hereditary angioedema: effect of androgen prophylaxis on plasma aminopeptidase P. J Allergy Clin Immunol 121:429-433

18. Pappalardo E, Zingale LC, Cicardi M (2003) Increased expression of C1-inhibitor mRNA in patients with hereditary angioedema treated with danazol. Immunol Lett 86:271-276

19. Shahidi NT (2001) A review of the chemistry, biological action, and clinical applications of anabolic-androgenic steroids. Clin Ther 23:1355-1390

20. Cheng MH, Yu BK, Chang SP, Wang PH (2005) A randomized, parallel, comparative study of the efficacy and safety of nafarelin versus danazol in the treatment of endometriosis in Taiwan. J Chin Med Assoc 68:307-314

21. Kahn H, Manzarbeitia C, Theise N, Schwartz M, Miller C, Thung SN (1991) Danazol-induced hepatocellular adenomas. A case report and review of the literature. Arch Pathol Lab Med 115:1054-1057
22. Schiavotto C, Castaman G, Rodeghiero F (1993) Treatment of idiopathic thrombocytopenic purpura (ITP) in patients with refractoriness to or with contraindication for corticosteroids and/ or splenectomy with immunosuppressive therapy and danazol. Haematologica 78:29-34

23. Craig TJ (2008) Appraisal of danazol prophylaxis for hereditary angioedema. Allergy Asthma Proc 29:225-231

24. Szeplaki G, Varga L, Valentin S, Kleiber M, Karadi I, Romics L et al (2005) Adverse effects of danazol prophylaxis on the lipid profiles of patients with hereditary angioedema. J Allergy Clin Immunol 115:864-869

25. Cicardi M, Castelli R, Zingale LC, Agostoni A (1997) Side effects of long-term prophylaxis with attenuated androgens in hereditary angioedema: comparison of treated and untreated patients. J Allergy Clin Immunol 99:194-196

26. Helsing P, Nielsen EW (2006) Hepatocellular focal nodular hyperplasia after danazol treatment for hereditary angio-oedema. Acta Derm Venereol 86:272-273

27. Bork K, Pitton M, Harten P, Koch P (1999) Hepatocellular adenomas in patients taking danazol for hereditary angio-oedema. Lancet 353:1066-1067

28. Bork K, Schneiders V (2002) Danazol-induced hepatocellular adenoma in patients with hereditary angio-oedema. J Hepatol 36:707-709

29. Monnier N, Ponard D, Duponchel C, Csopaki F, Bouillet L, Tosi M et al (2006) Characterisation of a new $\mathrm{C} 1$ inhibitor mutant in a patient with hepatocellular carcinoma. Mol Immunol 43:2161-2168

30. Farkas H, Varga L, Szeplaki G, Visy B, Harmat G, Bowen T (2007) Management of hereditary angioedema in pediatric patients. Pediatrics 120:e713-e722

31. Puukka K, Hietala J, Koivisto H, Anttila P, Bloigu R, Niemela O (2006) Age-related changes on serum ggt activity and the assessment of ethanol intake. Alcohol Alcohol 41:522-527

32. Cicardi M, Bergamaschini L, Tucci A, Agostoni A, Tornaghi G, Coggi $G$ et al (1983) Morphologic evaluation of the liver in hereditary angioedema patients on long-term treatment with androgen derivatives. J Allergy Clin Immunol 72:294-298

33. Zurlo JJ, Frank MM (1990) The long-term safety of danazol in women with hereditary angioedema. Fertil Steril 54:64-72

34. Creagh TM, Rubin A, Evans DJ (1988) Hepatic tumours induced by anabolic steroids in an athlete. J Clin Pathol 41:441-443

35. Weill BJ, Menkes CJ, Cormier C, Louvel A, Dougados M, Houssin D (1988) Hepatocellular carcinoma after danazol therapy. J Rheumatol 15:1447-1449

36. Bartley J, Loddenkemper C, Lange J, Mechsner S, Radke C, Neuhaus P (2004) Hepatocellular adenoma and focal nodular hyperplasia after long-term use of danazol for endometriosis: a case report. Arch Gynecol Obstet 269:290-293

37. Crampon D, Barnoud R, Durand M, Ponard D, Jacquot C, Sotto JJ et al (1998) Danazol therapy: an unusual aetiology of hepatocellular carcinoma. J Hepatol 29:1035-1036 